\title{
Formulation and Quality Evaluation of Fruit Peel Powder Incorporated Cookies
}

\author{
K. Mahalakshmi Sangeetha ${ }^{1 *}$ and P. Kavya ${ }^{2}$ \\ ${ }^{1}$ Associate Professor, Department of Foods and Nutrition, Rathnavel Subramaniam College of Arts and Science, \\ Coimbatore -641402, Tamil Nadu, India; sangeetha@rvsgroup.com \\ ${ }^{2}$ PG Student, Department of Foods and Nutrition, Rathnavel Subramainam College of Arts and Science, \\ Coimbatore - 641402, Tamil Nadu, India
}

\begin{abstract}
The study aims to develop Lemon peel, Orange peel and Pomegranate peel incorporated cookies and to analyse selected nutrients in the product. The Lemon peel powder, Orange peel powder and Pomegranate peel powder were prepared and incorporated in cookies in varying proportions by replacing maida. The standard along with the variations were subjected to sensory evaluation. Organoleptic evaluation showed $2 \%$ level of incorporation of lemon and orange peel powder and $5 \%$ level of pomegranate peel powder were acceptable in cookies. Fruit peels improved the nutritional properties of the cookies. From the study, it is concluded that the Lemon peel, Orange peel, Pomegranate peel powder can be incorporated in cookies at 2, 2 and 5 percent levels respectively without adversely affecting the quality attributes. Food use of fruit peel is a way to address food security and waste management issues.
\end{abstract}

Keywords: Cookies, Formulation, Lemon Peel, Orange Peel, Pomegranate Peel, Quality Assessment

\section{Introduction}

The convenience food segment is rapidly increasing, with the global ready-made foods market expected to grow by over $3 \%$ from about $\$ 1$ trillion in 2011 to nearly $\$ 1.5$ trillion in $2016^{1}$. Consumers have less time to shop, cook or prepare their foods due to urbanization and industrialization resulting in rapid expansion of convenience foods $s^{2}$.

Moisture content of cookies is comparatively lesser than cakes and bread, hence has longer shelf life and has lesser chance for microbial infestation ${ }^{3}$.

Roberts and Barnard ${ }^{4}$ reported a direct association between unbalanced diets and rising incidences of chronic health-related issues, including cardiovascular disease, diabetes and obesity. The consumption of lowfat, high-fibre foods has been advocated by health and nutrition agencies ${ }^{5}$.

Nowadays, demand for foods products with ingredients which contain bioactive compounds that provide additional health benefits are increasing ${ }^{6}$.

Fruits and vegetable processing in India generates substantial quantities of waste. It had been previously reported that these wastes and by-products of fruits are an abundant source of antioxidant polyphenols ${ }^{\underline{7}}$. These peels and pomace are a source of sugars, minerals and organic acids, dietary fibers and phenolics which have a wide range of actions which includes antioxidants, antimutagenic, cardio preventive, antibacterial and antiviral activities ${ }^{8}$. Use of waste as a source of polyphenols and antioxidants may have considerable economic benefit to food processors?

Globally, India is the leading producer of fruits. Fruit Peel is a valuable source of bioactive compounds, which can be converted into value-added products. Fruit Peel can 
be utilised as a substrate to bioactive compounds, phenolic antioxidants, organic acids, enzymes, biofertilizer, energy production and adsorbents ${ }^{10}$.

In view of the impact and economy of waste the present research investigation was carried out to utilize the fruit peel powder in value added food products viz: cookies and also evaluated for their quality characteristics. The utilization of these bioactive rich fruit residues can provide an efficient, inexpensive, and environment friendly platform for the production of novel nutraceuticals or for the improvement of older ones.

\section{Materials and Methods}

\subsection{Procurement of Ingredients}

Good quality refined wheat flour and other ingredients necessary for cookies preparation were procured from the local departmental stores.

Lemon peel, Orange peel and pomegranate peel were collected from fruit shops and dried $\left(\right.$ at $\left.60^{\circ} \mathrm{C}\right)$ and powdered in a grinder mill and sieved the sample particle size less than $0.2 \mathrm{~mm}$.

Pomegranates were initially cleaned, peeled and peel was dried for two or three days in a hygienic manner. The skin was ground into powder form ${ }^{11}$.

Pomogranate peels were cleaned and dried for 2 or 3 days in a hygienic condition and ground to a fine powder.

\subsection{Incorporation and Product Development}

Standard cookies were prepared with $100 \mathrm{~g}$ of refined wheat flour. Lemon peel powder and orange peel powder were incorporated at $2 \%, 4 \%, 6 \%, 8 \%$ while pomegranate peel powder was incorporated at 5\%,10\%,15\%, 20\% in preparation of fruit peel powder incorporated cookies.

The formulated and standard products were analyzed by 30 semi trained panel members from the Department of Foods and Nutrition, Rathnavel Subrmaniam College of Arts and Science based on the parameters like appearance, color, texture, flavor and taste for the selection of the best product. The best product of each incorporation was further analysed for nutrient content.

\subsection{Nutrient Analysis}

Iron and dietary fiber were estimated for standard and selected proportion of fruit peel incorporated cookies by AOAC method 12 .

\subsection{Statistical Analysis}

The data collected was statistically analysed using mean and standard deviation.

\section{Results and Discussion}

\subsection{Sensory Analysis}

The details regarding mean sensory scores obtained

Table 1. Mean Sensory Scores for Standard and Varying Proportions of Lemon Peel Powder Incorporated Cookies

\begin{tabular}{|c|c|c|c|c|c|c|}
\hline CRITERIA & \multirow{2}{*}{$\begin{array}{c}\text { MAXIMUM } \\
\text { SCORE }\end{array}$} & \multirow{2}{*}{$\begin{array}{c}\text { STANDARD } \\
\text { MEAN } \pm \text { SD }\end{array}$} & \multicolumn{4}{|c|}{ SAMPLE } \\
\cline { 4 - 7 } & & & $\mathbf{A}_{\mathbf{L}}(\mathbf{2 \%})$ & $\mathbf{B}_{\mathrm{L}} \mathbf{( 4 \% )}$ & $\mathbf{C}_{\mathrm{L}}(\mathbf{6 \%})$ & $\mathbf{D}_{\mathbf{L}}(\mathbf{8 \%})$ \\
\hline Appearance & 5 & $4.8 \pm 0.48$ & $4.8 \pm 0.48$ & $4.26 \pm 0.49$ & $3.66 \pm 0.43$ & $2.96 \pm 1.06$ \\
\hline Colour & 5 & $4.7 \pm 0.53$ & $4.6 \pm 0.49$ & $4.3 \pm 0.61$ & $3.83 \pm 0.83$ & $3 \pm 1.11$ \\
\hline Texture & 5 & $4.8 \pm 0.37$ & $4.6 \pm 0.47$ & $4.46 \pm 0.62$ & $3.83 \pm 0.79$ & $2.63 \pm 1.03$ \\
\hline Flavor & 5 & $4.8 \pm 0.34$ & $4.7 \pm 0.44$ & $4.4 \pm 0.67$ & $3.93 \pm 0.86$ & $2.83 \pm 0.94$ \\
\hline Taste & 5 & $4.66 \pm 0.62$ & $4.6 \pm 0.49$ & $4.5 \pm 0.82$ & $4.03 \pm 0.80$ & $2.8 \pm 1.09$ \\
\hline $\begin{array}{l}\text { Overall ac- } \\
\text { ceptability }\end{array}$ & 5 & $4.72 \pm 0.50$ & $4.6 \pm 0.76$ & $4.4 \pm 0.82$ & $3.85 \pm 0.59$ & $2.84 \pm 1.05$ \\
\hline
\end{tabular}


by standard and lemon peel incorporated cookies is given in (Table 1).

On incorporation of lemon peel powder, sample AL had a highest mean score of $4.6 \pm 0.76$ and sample DL, had a lowest mean score of $2.84 \pm 1.05$, whereas the sample BL, CL had values of $4.4 \pm 0.82$ and $3.85 \pm$ 0.59 respectively. Slight bitterness and colour change was observed on increasing the quantity of lemon peel powder in the cookies.

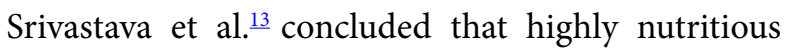
biscuits may be prepared by incorporating a level of 3\% of lemon peel powder without adversely affecting the overall acceptability of the product. In the present study 2
$\%$ incorporation in cookies was acceptable.

The details regarding mean sensory scores obtained by standard and orange peel incorporated cookies is given in (Table 2).

On incorporation of Orange peel powder sample Ao had a highest mean score of $4.48 \pm 0.62$ and sample Do, had a lowest mean score of $3.32 \pm 0.99$, whereas the sample Bo, Co have moderate values of $4.19 \pm 0.71$ and $3.32 \pm 0.99$ respectively. Due to bitterness and the strong flavor of peel, sample with low level of incorporation was highly acceptable than samples with higher level of incorporation of orange peel. Similar trend was observed in the study reported by Zaker et al (2016) 3 .

Table 2. Mean Sensory Scores for Standard and Varying Proportions of Orange Peel Powder Incorporated Cookies

\begin{tabular}{|c|c|c|c|c|c|c|}
\hline CRITERIA & $\begin{array}{c}\text { MAXIMUM } \\
\text { SCORE }\end{array}$ & STANDARD & \multicolumn{4}{|c|}{ SAMPLE } \\
& & MEAN \pm SD & & \multicolumn{4}{|c|}{ MEAN \pm SD } \\
\cline { 4 - 7 } & & & $\mathbf{A}_{\mathbf{o}}(\mathbf{2 \%})$ & $\mathbf{B}_{\mathbf{o}} \mathbf{( 4 \% )}$ & $\mathbf{C}_{\mathbf{o}} \mathbf{( 6 \% )}$ & $\mathbf{D}_{\mathbf{o}}(\mathbf{8} \%)$ \\
\hline Appearance & 5 & $4.8 \pm 0.48$ & $4.66 \pm 0.54$ & $4.13 \pm 0.77$ & $3.9 \pm 0.84$ & $3.56 \pm 0.97$ \\
\hline Colour & 5 & $4.7 \pm 0.53$ & $4.5 \pm 0.57$ & $4.06 \pm 0.69$ & $3.73 \pm 0.73$ & $3.36 \pm 0.99$ \\
\hline Texture & 5 & $4.8 \pm 0.37$ & $4.5 \pm 0.50$ & $4.3 \pm 0.70$ & $3.83 \pm 0.74$ & $3.23 \pm 1.00$ \\
\hline Flavor & 5 & $4.8 \pm 0.34$ & $4.3 \pm 0.79$ & $4.26 \pm 0.69$ & $3.76 \pm 0.77$ & $3.23 \pm 0.97$ \\
\hline Taste & 5 & $4.5 \pm 0.82$ & $4.46 \pm 0.68$ & $4.2 \pm 0.71$ & $3.86 \pm 0.77$ & $3.2 \pm 1.06$ \\
\hline $\begin{array}{c}\text { Overall ac- } \\
\text { ceptability }\end{array}$ & & $4.72 \pm 0.50$ & $4.48 \pm 0.62$ & $4.19 \pm 0.71$ & $3.82 \pm 0.65$ & $3.32 \pm 0.09$ \\
\hline
\end{tabular}

Table 3. Mean Sensory Scores for Standard and Varying Proportions of Pomegranate Peel Powder Incorporated Cookies

\begin{tabular}{|c|c|c|c|c|c|c|}
\hline \multirow[t]{3}{*}{ CRITERIA } & \multirow{3}{*}{$\begin{array}{c}\text { MAXIMUM } \\
\text { SCORE }\end{array}$} & \multirow{3}{*}{$\begin{array}{l}\text { STANDARD } \\
\text { MEAN } \pm S D\end{array}$} & \multirow{2}{*}{\multicolumn{4}{|c|}{$\begin{array}{c}\text { SAMPLE } \\
\text { MEAN } \pm \text { SD }\end{array}$}} \\
\hline & & & & & & \\
\hline & & & $\mathbf{A}_{\mathrm{p}}$ & $\mathbf{B}_{\mathrm{p}}$ & $\mathrm{C}_{\mathrm{p}}$ & $\mathrm{D}_{\mathrm{P}}$ \\
\hline Appearance & 5 & $4.8 \pm 0.48$ & $4.56 \pm 0.56$ & $4.1 \pm 0.71$ & $3.43 \pm 0.85$ & $2.80 \pm 1.03$ \\
\hline Colour & 5 & $4.7 \pm 0.53$ & $4.43 \pm 0.56$ & $4.13 \pm 0.68$ & $3.33 \pm 0.89$ & $2.80 \pm 1.20$ \\
\hline Texture & 5 & $4.8 \pm 0.37$ & $4.46 \pm 0.50$ & $4.06 \pm 0.73$ & $3.36 \pm 0.92$ & $2.73 \pm 1.04$ \\
\hline Flavor & 5 & $4.8 \pm 0.34$ & $4.53 \pm 0.53$ & $3.93 \pm 0.82$ & $3.33 \pm 0.95$ & $2.7 \pm 0.95$ \\
\hline Taste & 5 & $4.66 \pm 0.62$ & $4.5 \pm 0.50$ & $3.96 \pm 0.80$ & $3.36 \pm 0.80$ & $2.62 \pm 1.06$ \\
\hline $\begin{array}{l}\text { Overall ac- } \\
\text { ceptability }\end{array}$ & 5 & $4.72 \pm 0.50$ & $4.5 \pm 0.53$ & $4.03 \pm 0.89$ & $3.36 \pm 0.88$ & $2.73 \pm 0.78$ \\
\hline
\end{tabular}


The details regarding mean sensory scores obtained by standard and orange peel incorporated cookies is given in (Table 3).

On incorporation of pomegranate peel powder, sample AP had a highest mean score of $4.5 \pm 0.53$ and sample DP, had a lowest mean score of $2.62 \pm 1.06$, whereas the sample BP, CP had moderate scores of $3.96 \pm 0.80$ and 3.36 \pm 0.88 respectively. Samples with higher concentration of pomegranate peel are less acceptable than samples with low concentration because of the bitterness and dark discoloration when compared with standard.

The organoleptic properties of idli were evaluated for Aroma, Appearance, Fluffiness, Compactness, Sponginess, Taste, Firmness, Springiness, Stickiness and overall acceptability. The overall acceptability and rating scale score was higher for the $10 \%$ level of incorporation after which increasing the level of pomegranate skin powder affected the sensory qualities $\underline{\underline{11}}$. In the present study, cookies prepared with $5 \%$ level of pomegranate peel was more acceptable and overall acceptability of the cookies decreased as the percentage of incorporation of the pomegranate peels increased.

\subsection{Nutrient Analysis}

The details regarding iron content of Lemon peel, Orange peel and Pomegranate peel incorporated cookies (per 100g) is given in (Figure 1).

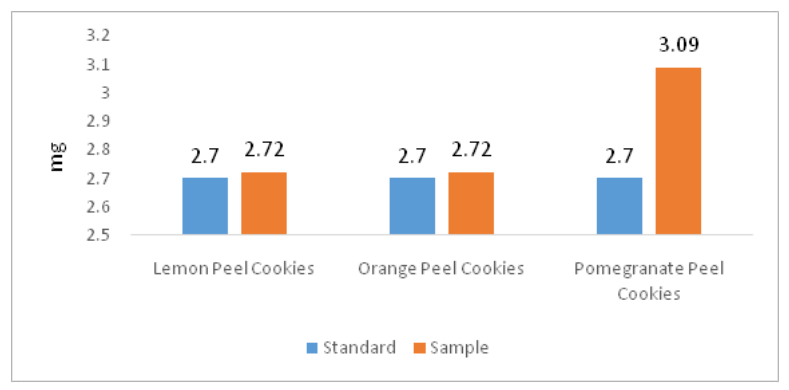

Figure 1. Iron content of standard and selected variation of fruit peel powder incorporated cookies.

There is an increase in iron content of Lemon peel and orange peel cookies by $0.02 \mathrm{mg}$ and Pomegranate peel cookies by 0.39 . The negligible increase in iron content is contributed by the substitution of fruit peel instead of Maida.

The details regarding fibre content of Lemon peel, Orange peel, Pomegranate peel incorporated cookies (per $100 \mathrm{~g}$ ) is given in (Figure 2).

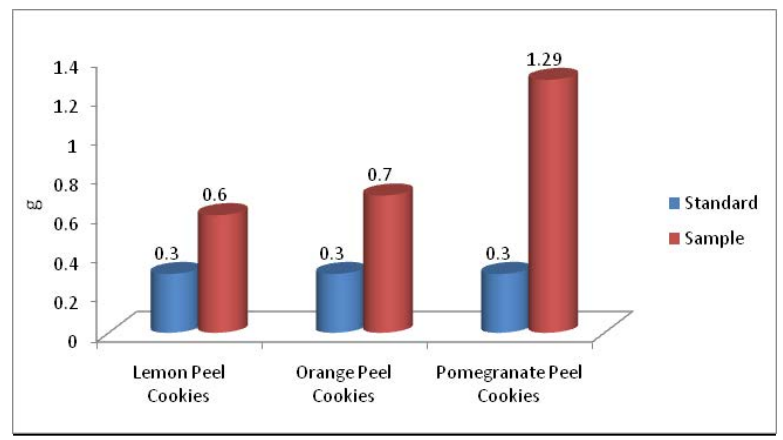

Figure 2. Fiber content of standard and selected variation of fruit peel powder incorporated cookies.

The fibre content of Lemon peel cookies increased by $0.3 \mathrm{~g}$, Orange peel cookies by $0.4 \mathrm{~g}$ and Pomegranate peel cookies by $0.99 \mathrm{~g}$. Fiber content of sample cookies increased because of addition of fruit peel. The study by Obafaye and Omoba showed that there was significant increase in antioxidant properties and dietary fiber with increase in Orange Peel. Pomegranate Peel powder supplementation significantly $(\mathrm{p}<0.05)$ improved dietary fibers $(0.32-01.96 \mathrm{~g} / 100 \mathrm{~g})$, total phenols $(90.7-161.9 \mathrm{mg}$ $\mathrm{GAE} / 100 \mathrm{~g})$ and inorganic residues $(0.53-0.76 \mathrm{~g} / 100 \mathrm{~g})$ of cookies ${ }^{14}$.

\section{Conclusion}

Fruit peels are agricultural waste generated during the production of fruit juice and are valuable natural sources of antioxidants and dietary fiber. They have the potential to be an effective tool in managing chronic degenerative diseases related to oxidative stress. The Peels can be exploited to produce functional snacks and exposing consumers to new source of antioxidants and dietary fiber. It will also minimize waste and provide value addition to byproducts that are considered as waste in agricultural processing.

\section{References}

1. Rivera XCS, Orias NE and Azapagic A. Life cycle environmental impacts of convenience food: Comparison of ready and home-made meals. Journal of Cleaner Production. 2014; 73:294-309. https://doi.org/10.1016/j. jclepro.2014.01.008

2. Scholliers P. Convenience foods. What, why, and when. Appetite. 2015; 94:2-6. https://doi.org/10.1016/j. appet.2015.02.017 PMid:25683795 
3. Zaker MA, Sawate AR, Patil BM and Sadawarte SK. Studies on Effect of Orange Peel Powder Incorporation on Physical, Nutritional and Sensorial Quality of Cookies. International Journal of Engineering Research and Technology. 2016; 5(09):78-82. https://doi.org/10.17577/IJERTV5IS090125

4. Roberts CK and Barnard RJ. Effects of exercise and diet on chronic disease. Journal of Applied Physiology. 2005; 98(1):3-30. https://doi.org/10.1152/japplphysiol.00852.2004 PMid: 15591300

5. Martinez-Monzo J, Garcia-Segovia P and Albors-Ga'rrigos J. Trends and innovations in bread, bakery, and pastry. Journal of Culinary Science and Technology. 2013; 11(1):5665. https://doi.org/10.1080/15428052.2012.728980

6. Mironeasa S, Codina GG. Effect of citrus fibers addition on wheat flour dough rheological properties. Food and Environment Safety. 2013; 12(4):322-7.

7. Balasundram N, Sundaram K, Samman S. Phenolic compounds in plants Andagri-industrial by-products: Antioxidant activity, occurrence, and potential uses. Food Chemistry. 2016; 99:191-203. https://doi.org/10.1016/j. foodchem.2005.07.042

8. Adams LS, Seeram NP, Agarwal BB, Takada Y, Sand D, et al. Pomegranate juice, total pomegranate ellagitannins, and punicalagin suppress inflammatory cell signaling in colon cancer cells. Journal of Agricultural and Food Chemistry.
2006; 54:980-5. https://doi.org/10.1021/jf052005r PMid:16448212

9. Singh S, Immanuel G. Extraction of Antioxidants from Fruit Peels and its Utilization in Paneer. Journal of Food Processing and Technology. 2014; 5:349.

10. Pathak PD, Mandavgane SA and Kulkarni PD. Fruit peel waste: characterization and its potential uses. Current Science. 2017; 113(3):444-54. https://doi.org/10.18520/cs/ v113/i03/444-454

11. Fathima S, Puraikalan YD. Development of Food Products Using Pomegranate Skin. International Journal of Science and Research (IJSR). 2013; 4(3):1756-8.

12. Obafaye RO and Omoba OS. Orange peel flour: A potential source of antioxidant and dietary fiber in pearlmillet biscuit. Journal of Food Biochemistry. 2018; 42(1):8. https://doi.org/10.1111/jfbc.12523

13. Srivastava N, Yadav KC, Verma P, Kishore K, Rout S. Development of Lemon Peel Powder and its Utilization in Preparation of Biscuit by Different Baking Methods. International Journal for Scientific Research and Development. 2015; (08):709-12.

14. Ismail T, Akhtar S, Riaz M \& Ismail A, "Effect of pomegranate peel supplementation on nutritional, organoleptic and stability properties of cookies", International Journal of Food Sciences and Nutrition. 2014; 65(6):661-666. 